\title{
A Cross Cultural Study on Effect of Parental Education and Occupation on Cognitive Development of Children
}

\author{
Sangeeta Sidola*and Bimla Dhanda \\ Department of Human Development and Family Studies, College of H.Sc., Chaudhary Charan \\ Singh Haryana Agricultural University, Haryana (125 004), India \\ *Corresponding author
}

Keywords

Cognitive development, Parental education and parental occupation

Article Info

Accepted:

07 January 2019

Available Online:

10 February 2019

\section{A B S T R A C T}

Cognitive development is very important for the overall development of the children and early years play a pivotal role in the brains development. The attachments the children form with their parents and the kind of environment they get highly effect their cognitive development. The early years are best to invest on the children for ensuring their future success. The parents are the children first educator and they affect child in their development. The kind of exposure and healthy environment a child has during the early years can either support learning or interfere with it. The parental educational level and parental occupation has a significant impact on child outcomes as they impact the child in both the positive and negative way. The study focuses on the effect of parental education and occupation on cognitive development of children. The study was conducted on the rural and urban area of state Haryana and state Uttarakhand, the sample comprises of total 200 children age range 3 years and the data was collected from the Aaganwadis. The results of the study indicated that the father and mother education of both the states has a significant impact on the cognitive development of the children. The mother occupation was associated with cognitive development of the children of urban areas of both states whereas the father occupation was not associated with the cognitive development of the children.

\section{Introduction}

The early childhood child do not imagine or respond in the manner as we adult think and respond, their brain have not yet developed at its fullest as of the adults. The various studies on cognitive development look at the development and behaviour of the brain and attempts to understand how brain develops and thoughts changes from birth to adulthood. Early childhood is a tremendously accelerate stage of brain development and children first start on to expand their logics and thinking process in the early years. Parents play a very major role in shaping the cognitive development of the child. The literature available on effect of parental background on the cognitive skills of the children has showed that it had a significant effect on children outcome (Black et al., 2011). As parents can affect the actions and the behaviour as well as the decision made by their children all the 
way through heredity, choices and environment which means parents who are educated and well working can afford a better, healthier and superior environment to their children which will result in advance development of the children (McLachlan et al., 2013). The home environment and parental education are important predictors of cognitive abilities. It has seen that it is very essential for the parents to manage the cognitive capacities of the children and to the parents who are less educated to encourage and participate with children (Biedinger 2011).

Children's health and cognitive development tend to be higher when parents have more education. The parental education had an impact on their children's brain structure too, with inspection enlightening a larger hippocampus in children from more educated families. The hippocampus area of the brain plays essential role in short term memory and spatial navigation (Nobel et al., 2015). The educated mother will give more opportunities and keep track of the child's growth and development. The educated parents are aware about the Child's needs and requirements and contribute positively in their development. The first three years of life are a particularly important period for children (Carnegie Task Force on Meeting the Needs of Young Children, 1994; Council of Economic Advisers, 1997). Research give emphasis to the effects of early influences on brain development (Shore, 1997) and the first years are likely to be significant for the development of self-esteem, emotional stability and learning proficiency. The efforts and dedication by the parents during early childhood may therefore encourage healthy development.

Work force involvement during the second and third years has predominantly harmful consequences if the mother is working for the long hours or was also in a job in the first year. The findings are strong to the enclosure of management for day care arrangements or paternal employment. There are some signs that early work may be mainly valuable for children in "conventional" two-parent families and the findings also suggest the importance of involvement of fathers. The parents, especially mother occupation can be beneficial for the children as they will be economically able to fulfill child's demand (Heinrich 2014) In contrary, the study provides a more negative assessment of the impact of early employment than most prior research as they see the development of the children is not in a healthy manner and it also impact their later development (Ruhm, 2002). The mothers' exposure to work-related hazards negatively affects children's cognitive development (Felfea and Hsinc, 2012). Mother employment during the early three years of the child's life is envisaged to have a small harmful cause on the verbal aptitude of 3 and 4 year olds children and a considerable negative impact on the math and reading attainment of 5 and 6 year olds children. While there are harmful consequences of working mother on children, they are able to contribute to children growth and improvement weigh against to non-working mothers and it was envisaged that mothers' logical, rational and financial wealth contribute to children educational and cognitive development (Alam and Noor 2012). Other than this culture also play a significant role in child's cognitive development as the children living in rural poverty are distinct from the children living in urban poverty in their working memory profile (Tine, 2013). Rowley and Camacho (2016) in their study envisaged that Race, culture, ethnicity, and economic background comprise powerful impact on children's mental ability and behavior.

So keeping these views in mind the following objectives has been framed to find out the results: 
To assess the level of parental education and parental occupation of the children.

To see the effect of parental education and occupation on cognitive development of the children.

\section{Materials and Methods}

As per the objectives, state Uttarakhand and state Haryana of India were selected purposively due to easy accessibility. The study was conducted in urban and rural areas of Haryana and Uttarakhand states. Hisar district of Haryana and Pauri district of Uttarakhand were selected randomly.

The age group for the study was 3 years old children ( \pm 15 days). To draw rural sample from both the states, a list of children of anganwadis were prepared and 50 children were selected randomly, similarly to draw urban sample from both the states, a list of balwadis /urban anganwadis were prepared and 50 children were selected randomly, regardless of their gender. Hence the total numbers of the samples were 200 children for the present study.

\section{Instrument used}

Bayley scale of infant and toddler development for 3 year

Bayley scale of infant development by Nancy Bayley (2006) was used to test the cognitive level of children.

\section{Home environment inventory}

Home inventory by Caldwell and Bradley (1984) was used to judge the environmental conditions of children's home.

\section{Results and Discussion}

Table 1 envisaged the educational level and occupation of the parents of the children and the educational status of the mother highlighted that in state Uttarakhand and state Haryana also mostly the women are more illiterate. As far as Father Education is concerned, in both the states the data reveals they are up to matriculation.

Occupational status of the mother of respondents revealed that in state Uttarakhand and state Haryana majority of the mothers were home maker. Turning towards occupation of the father data highlighted that in state Uttarakhand more fathers were involved in farming. While in state Haryana fathers were more involved in private jobs.

Table 2 reveals the association of cognitive development with mother education. Among rural area children of Uttarakhand it was seen that cognitive development was associated with birth order. $\left(\chi^{2}=6.30\right)$ at 0.05 level of significance. While in rural area of Haryana cognitive development of children was associated with birth order $\left(\chi^{2}=7.20\right)$ at 0.05 level of significance.

Table 3 highlighted the association of cognitive development with mother education. It was observed that in urban area of Uttarakhand, cognitive development of children was associated with the mother education $\left(\chi^{2}=6.78\right)$ at 0.05 level of significance. Also in urban area of Haryana cognitive development of the children was associated with mother education. $\left(\chi^{2}=7.35\right)$.

Table 4 elucidates the association of cognitive development with father education in rural areas of both states. It was observed that cognitive development of Haryana rural area children was associated with father education $\left(\chi^{2}=7.31\right)$ at 0.05 level of significance.

While cognitive development of Uttarakhand rural area children was not associated with father education. 
Table 5 explicate that statistically significant association existed in between cognitive development with father education in urban area of both Uttarakhand and Haryana $\left(\left(\chi^{2}=\right.\right.$ 8.90 and 10.87 respectively) at 0.05 level of significance.

Table 6 reveals the association of cognitive development with mother occupation. It was observed that in rural area of both the states cognitive development of children was not associated with mother occupation.

Table 7 highlighted the association of cognitive development with mother occupation. Among urban area children of
Uttarakhand it was observed that cognitive development was associated with mother occupation $\left(\chi^{2}=9.40\right)$ at 0.05 level of significance. Similarly in urban area of Haryana cognitive development was associated with mother occupation $\left(\chi^{2}=\right.$ 11.20 ) at 0.05 level of significance.

Table 8 reveals the association between cognitive development and father occupation. It was observed that in rural areas of Uttarakhand and Haryana states cognitive development was not associated with the occupation of father.

Table.1 Profile of Parental education and occupation

\begin{tabular}{|l|c|c|c|c|c|c|}
\hline Mother's education & \multicolumn{3}{|c|}{ Uttarakhand (n=100) } & \multicolumn{3}{c|}{ Haryana (n=100) } \\
\hline & Rural & Urban & Total & Rural & Urban & Total \\
\hline Illiterate & $26(32)$ & $18(36)$ & 44 & $28(56)$ & $16(30)$ & 44 \\
\hline Up to matriculation & $14(30)$ & $20(40)$ & 34 & $12(24)$ & $21(42)$ & 33 \\
\hline $\begin{array}{l}\text { Matriculation to } \\
\text { graduation }\end{array}$ & $10(20)$ & $12(24)$ & 22 & $10(20)$ & $13(26)$ & 23 \\
\hline Father's education & & & & & \\
\hline Illiterate & $18(36)$ & $14(28)$ & 32 & $17(34)$ & $13(26)$ & 30 \\
\hline Up to Matriculation & $21(42)$ & $20(40)$ & 41 & $22(44)$ & $22(44)$ & 44 \\
\hline $\begin{array}{l}\text { Matriculation to } \\
\text { graduation }\end{array}$ & $11(22)$ & $16(32)$ & 27 & $11(22)$ & $15(30)$ & 26 \\
\hline Mother's occupation & & & & & & \\
\hline Home maker & $36(72)$ & $30(60)$ & 66 & $38(76)$ & $35(70)$ & 73 \\
\hline Govt. Job & $12(24)$ & $14(28)$ & 26 & $05(10)$ & $10(20)$ & 15 \\
\hline Private job & $02(04)$ & $06(12)$ & 8 & $07(14)$ & $05(10)$ & 12 \\
\hline Father's occupation & & & & & & \\
\hline Farming & $28(56)$ & $05(10)$ & 38 & $07(14)$ & $02(04)$ & 9 \\
\hline Govt. Job & $12(24)$ & $26(52)$ & 33 & $10(20)$ & $13(26)$ & 23 \\
\hline Private job & $10(20)$ & $19(38)$ & 29 & $33(66)$ & $35(70)$ & 68 \\
\hline
\end{tabular}


Table.2 Association of cognitive development with mother's education in rural areas of both states

\begin{tabular}{|l|cc|}
\hline \multicolumn{1}{|c|}{ BSID } & Mother's Education & $\mathbf{n = 1 0 0}$ \\
\hline & Uttarakhand $(\mathbf{n}=\mathbf{5 0})$ & Haryana $(\mathbf{n = 5 0})$ \\
\cline { 2 - 3 } Scores & $\chi^{2}$ & $\chi^{2}$ \\
\hline *Significant at $5 \%$ level of significance; Figures in parentheses indicate percentage & $7.20 *$ \\
\hline
\end{tabular}

Table.3 Association of cognitive development with mother's education in urban areas of both states

\begin{tabular}{|l|cc|}
\hline \multicolumn{1}{|c|}{ BSID } & Mother's Education & $\mathbf{n = 1 0 0}$ \\
\hline & Uttarakhand $(\mathbf{n}=\mathbf{5 0})$ & Haryana $(\mathbf{n = 5 0})$ \\
\cline { 2 - 3 } Scores & $\chi^{\mathbf{2}}$ & $\chi^{\mathbf{2}}$ \\
\hline *Significant at $\mathbf{5} \%$ level of significance; Figures in parentheses indicate percentage \\
\hline
\end{tabular}

Table.4 Association of cognitive development with father's education in rural areas of both states

\begin{tabular}{|l|cc|}
\hline \multicolumn{1}{|c|}{ BSID } & Father's Education & $\mathbf{n = 1 0 0}$ \\
\hline & Uttarakhand $(\mathbf{n}=\mathbf{5 0})$ & Haryana $(\mathbf{n = 5 0})$ \\
\cline { 2 - 3 } & $\chi^{\mathbf{2}}$ & $\chi^{\mathbf{2}}$ \\
\hline Scores & 4.98 & $7.31 *$ \\
\hline "Significant at 5 \% level of significance; Figures in parentheses indicate percentage \\
\hline
\end{tabular}

Table.5 Association of cognitive development with father's education in urban areas of both states

\begin{tabular}{|l|cc|}
\hline \multicolumn{1}{|c|}{ BSID } & Father's Education & $\mathbf{n}=\mathbf{1 0 0}$ \\
\hline & Uttarakhand $(\mathbf{n}=\mathbf{5 0})$ & Haryana $(\mathbf{n = 5 0})$ \\
\cline { 2 - 3 } Scores & $\chi^{\mathbf{2}}$ & $\chi^{\mathbf{2}}$ \\
\hline * Significant at $5 \%$ level of significance; Figures in parentheses indicate percentage \\
\hline
\end{tabular}


Table.6 Association of cognitive development with mother's occupation in rural areas of both states

\begin{tabular}{|l|cc|}
\hline \multicolumn{1}{|c|}{ BSID } & Mother's Occupation & $\mathbf{n}=\mathbf{1 0 0}$ \\
\hline & Uttarakhand $(\mathbf{n}=\mathbf{5 0})$ & Haryana $(\mathbf{n}=\mathbf{5 0})$ \\
\cline { 2 - 3 } & $\chi^{\mathbf{2}}$ & $\chi^{\mathbf{2}}$ \\
\hline Scores & 3.33 & 4.62 \\
\hline *Significant at $\mathbf{5} \%$ level of significance; Figures in parentheses indicate percentage \\
\hline
\end{tabular}

Table.7 Association of cognitive development with mother's occupation in urban areas of both states

\begin{tabular}{|l|cc|}
\hline \multicolumn{1}{|c|}{ BSID } & Mother's Occupation & $\mathbf{n}=\mathbf{1 0 0}$ \\
\hline & Uttarakhand $(\mathbf{n}=\mathbf{5 0})$ & Haryana $(\mathbf{n}=\mathbf{5 0})$ \\
\cline { 2 - 3 } & $\chi^{2}$ & $\chi^{2}$ \\
\hline Scores & $9.40 *$ & $11.20^{*}$ \\
\hline *Significant at $5 \%$ level of significance; Figure in parentheses indicate percentage \\
\hline
\end{tabular}

Table.8 Association of Cognitive Development with father's occupation in rural areas of both states

\begin{tabular}{|l|c|c|}
\hline \multicolumn{1}{|c|}{ BSID } & Father's Occupation & $\mathbf{n = 1 0 0}$ \\
\hline & Uttarakhand $(\mathbf{n}=\mathbf{5 0})$ & Haryana $(\mathbf{n = 5 0})$ \\
\cline { 2 - 3 } & $\chi^{\mathbf{2}}$ & $\chi^{\mathbf{2}}$ \\
\hline Scores & 1.44 & 2.40 \\
\hline *Significant at $5 \%$ level of significance; Figures in parentheses indicate percentage \\
\hline
\end{tabular}

Table.9 Association of Cognitive Development with father's occupation in urban areas of both States

\begin{tabular}{|l|c|c|}
\hline \multicolumn{1}{|c|}{ BSID } & Father's Occupation & $\mathbf{n}=\mathbf{1 0 0}$ \\
\hline & Uttarakhand $(\mathbf{n}=\mathbf{5 0})$ & Haryana $(\mathbf{n}=\mathbf{5 0})$ \\
\cline { 2 - 3 } & $\chi^{\mathbf{2}}$ & $\chi^{\mathbf{2}}$ \\
\hline Scores & 3.69 & 4.43 \\
\hline *Significant at $\mathbf{5} \%$ level of significance; Figures in parentheses indicate percentage \\
\hline
\end{tabular}

Table 9 highlighted the association of cognitive development and father occupation. It was observed that in urban areas of both the states cognitive development was not associated with the occupation of father.
In conclusion, the parental education and mother's occupation play a very significant role in children cognitive development therefore it can be concluded that the child's cognitive development had a significant 
impact of Mother's education, father's education and mother occupation.

\section{References}

Alam, M., Noor, Z. 2012. Mothers' Perception on the Impact of Employment on their Children: Working and Non-working Mothers. International Journal of Social Sciences. 2. 10.7718 .

Biedinger, N., 2011.The Influence of Education and Home Environment on the Cognitive Outcomes of Preschool Children in Germany Child Development Research, Article ID 916303, $\quad 10 \quad$ pages. http://dx.doi.org/10.1155/2011/916303

Black, S.E., Devereux, P.J., Salvanes, K.G., 2005. Why the apple doesn't fall far: understanding Intergenerational transmission of human capital. American Economic Review, 95(1):437-449.

Felfea, C., Hsinc, A., 2012. Maternal work conditions and child development Economics of Education Review. 31(6): 1037-1057.

Heinrich, C.J., 2014. Parents' Employment and Children's Wellbeing. The Future of children 24(1)

McLachlan, R., Gilfillan, G., Gordon, J.,
2013.Deep and Persistent Disadvantage in Australia. Australian Government Productivity Commission Staff Working Paper. Australian Government Productivity Commission, Canberra, Australia.

Noble, K.G., Houston,S.M., Brito, N.H., Bartsch, H., Kan,E., Kuperman,J.M., Akshoomoff, N., Gruen J.R., Kennedy, D.N, Van Zijl, P., Mostofsky, S., Kaufmann, W.E., Kenet, T., Dale, A.M., Jernigan, T.L., Sowell, E.R., Family Income, 2015 Parental Education and Brain Structure in Children and Adolescents. Nature Neuroscience, 18, 5.773-8.

Rowley, S. J. and Camacho, T. C (2016) Increasing diversity in cognitive developmental research: issues 'and solutions. Journal of Cognition and Development, 16(5):683-692.

Ruhm, J., 2000. Parental Employment and Child Cognitive Development Christopher. Journal of Human Resources 39(1)

Shore, Rima. 1997. Rethinking the brain: new insights into early development. New York: Families and Work Institute.

Tine, M., 2013 Working memory differences between children living in rural and urban poverty. Journal of Cognition and Development, 15(4), 599-613.

\section{How to cite this article:}

Sangeeta Sidola and Bimla Dhanda. 2019. A Cross Cultural Study on Effect of Parental Education and Occupation on Cognitive Development of Children. Int.J.Curr.Microbiol.App.Sci. 8(02): 580-586. doi: https://doi.org/10.20546/ijcmas.2019.802.065 